\title{
EL INDIGENISMO CARDENISTA Y LA RENOVACIÓN DE LA CLASE POLÍTICA CHIAPANECA (1936-1940)
}

Ma. Dolores París Pombo

UAM Xochimilco

\section{RESUMEN}

Este artículo ${ }^{1}$ analiza las dos caras del indigenismo en Los Altos de Chiapas durante el gobierno de Efraín Gutiérrez (1936-1940) en el estado: por un lado, el indigenismo del gobierno federal, a través del Departamento de Asuntos Indígenas (DAI); por el otro, el del gobierno estatal, mediante el Departamento de Acción Social, Cultura y Protección Indígena (DASCPI). Mientras que el primero buscó la incursión de la acción política posrevolucionaria en regiones que seguían controladas por grupos locales de poder poco afines al presidente Lázaro Cárdenas, el segundo emprendió la transformación de las estructuras locales de poder para abrir las puertas a un sector mestizo e indígena originario de la región, que había sido hasta entonces marginado de los cargos públicos. Durante estos años, ese sector pasaría a renovar la clase política chiapaneca.

\section{INTRODUCCIÓN}

Durante el gobierno de Lázaro Cárdenas del Río (1934-1940), el indigenismo constituyó uno de los pilares ideológicos del naciente Estado posrevolucionario. Su principal objetivo, planteado por un grupo de intelectuales mestizos cercanos al nuevo régimen político y por el propio presidente en sus giras por la república mexicana, era "la integración de los indígenas a la nación mexicana" o la "mexicanización del indio". En consecuencia, la élite política puso en marcha un aparato institucional tanto en el ámbito federal como en los distintos estados de la república, para diseñar y ejecutar 
programas de integración y políticas sociales —educativas, agrarias, productivas y de salud - en regiones y comunidades con alta proporción de población indígena. Los funcionarios públicos encargados de estas tareas actuaban muchas veces con evidente desconocimiento de las regiones y comunidades indígenas. Por su parte, los pueblos indios fueron considerados como destinatarios y no como copartícipes de las políticas indigenistas. Sin embargo, no fueron receptores pasivos: la intervención de nuevos actores políticos y la entrada de instituciones federales a regiones que habían permanecido relativamente aisladas, dio lugar a una profunda transformación de las redes locales de poder. Abrió así las puertas para la formación de nuevos liderazgos en las comunidades y regiones indígenas, la renovación del sistema de cargos y de elección de autoridades comunitarias.

El estado de Chiapas fue particularmente privilegiado por los indigenistas. En particular, la región de Los Altos —Meseta Central— constituyó en la época un verdadero laboratorio de las políticas de asimilación. Además de la intervención de instituciones federales como la Secretaría de Educación Pública y el Departamento de Asuntos Indígenas, el gobierno estatal implementó en las comunidades todo tipo de medidas destinadas a la incorporación y al "mejoramiento de la raza indígena", desde programas de castellanización hasta la organización de comités agraristas y sindicatos indígenas.

La labor del indigenismo cardenista en Los Altos de Chiapas ha sido analizada por diversos autores: Rus (1995), Collier (1987), Wasserstrom (1989), Benjamin (1990), Lewis (2001 y 2005), como un proceso político de cooptación de las autoridades comunitarias en favor del partido oficial, de corporativización de los indígenas tsotsiles 
y tseltales y un pretexto para la incursión de las instituciones federales en la región. Otros autores —Favre (1984), García de León (1985)— han puesto el énfasis en el papel disruptivo del indigenismo en Chiapas, es decir, en la transformación de las estructuras tradicionales de poder, el desplazamiento de la oligarquía criolla y la integración de indígenas y mestizos a la vida política del estado.

En este artículo sostengo que el indigenismo de los años treinta no puede analizarse solamente desde la perspectiva del Estado federal; tiene que estudiarse también como un movimiento político regional que propició la renovación de la clase política chiapaneca. El surgimiento de nuevos sectores dirigentes tanto en las comunidades indígenas, en las ciudades, como en el gobierno del estado, permitió por primera vez la realización de importantes reformas sociales tales como el reparto agrario, desplazando muchas veces de las instituciones políticas a los terratenientes y a las familias criollas que habían conservado hasta entonces el poder local. De esta forma, abrió espacios de participación política a grupos socioétnicos que habían sido hasta entonces marginados de las instituciones regionales.

\section{VIEJAS OLIGARQUÍAS Y COMUNIDADES INDÍGENAS}

En el periodo posrevolucionario, las élites políticas chiapanecas estaban divididas en redes familiares y regiones de influencia. Algunas zonas del estado seguían muy aisladas, tanto del centro del país como de la capital, lo cual favorecía la formación de cacicazgos y la reproducción de clivajes étnicos y políticos. En buena parte de Chiapas, se reproducían algunas características sociales coloniales, como el trabajo indígena servil o esclavo, la segregación territorial y la dominación patriarcal. 
En la región de Los Altos, San Cristóbal de Las Casas ${ }^{2}$ era una ciudad fundamentalmente blanca, y mantenía la hegemonía sobre un amplio territorio poblado en su mayoría por pueblos indígenas. Unas cuantas familias criollas - llamadas "coletas"- conservaban el control político y económico sobre el hinterland. El gobierno local de los pueblos tsotsiles y tseltales estaba a cargo de secretarios municipales nombrados por el gobierno del estado —a sugerencia de la presidencia municipal de Las Casas-, quienes administraban el presupuesto y se hacían cargo de todos los asuntos administrativos. Muchos de estos secretarios eran enganchadores o distribuidores de alcoholes.

Los habitantes de Las Casas dependían tanto de las comunidades indígenas como éstas de la ciudad; en efecto, los principales ingresos de los comerciantes mestizos y criollos provenían de la venta de aguardiente a los indígenas y del enganche hacia tierras bajas: un complejo sistema de intermediación para habilitar a los trabajadores indígenas en sus comunidades y conducirlos hasta las fincas cafetaleras y bananeras de la costa del Pacífico, hacia las fincas de Pichucalco o de los valles del Grijalva.

Las estructuras de poder en Los Altos estaban permeadas por una cultura racista, de tal modo que para las familias más acomodadas, el indígena era considerado abiertamente una más de las posesiones o de los "recursos naturales" de la región. Era frecuente el trabajo indígena no pagado y el asalto a los indígenas que llegaban a vender sus mercancías a la ciudad. En contraparte, las comunidades de Los Altos estaban consideradas por los ladinos como territorios salvajes y peligrosos. Corría así el rumor 
de que "Si te agarraba la noche en Chamula, podías irte a dormir... pero no amanecerías" (Rus 1995: 256).

Las relaciones interétnicas eran no solo de desigualdad y explotación, también de violencia: las fincas se encontraban custodiadas por ejércitos privados —llamados "guardias blancas"-; los enganchadores, encargados de contratar peones y conducirlos hacia las fincas cafetaleras del Soconusco, tenían sus propios pistoleros, e incluso los comerciantes de aguardiente viajaban por la región con guardaespaldas fuertemente armados. Este clima de violencia propició en muchos pueblos una suerte de retraimiento comunitario: el poder municipal quedó en manos de indígenas ancianos monolingües, con dominio y prestigio político-religioso en la comunidad, pero que no tenían ninguna injerencia en la intermediación económica con los ladinos o en el sistema de enganche (Collier 1987, Rus 1995, Lewis 2001).

Abundan, en los años treinta, los episodios violentos de enfrentamiento entre pobladores indígenas y ladinos — blancos y mestizos, hablantes de castellano- que habitaban en las cabeceras de los municipios. Muchos de estos estallidos fueron provocados por la campaña anticlerical del gobernador Victórico Grajales (1932-1936). Otros conflictos ponían al desnudo las luchas por el control territorial y el comercio del aguardiente. Así, a inicios de 1935, una rebelión que se inició en Cancuc se fue extendiendo a Larráinzar y Chenalhó. Los secretarios municipales de esos pueblos se comunicaban cotidianamente con el presidente municipal de Las Casas solicitando urgentemente la presencia del ejército debido a que los indígenas pretendían asesinarlos y expulsar a los ladinos. Los levantamientos se dieron fundamentalmente por el control de la venta al menudeo de aguardiente. El 28 de febrero de ese año, el presidente municipal, Evaristo 
Bonifaz, manifestaba al secretario de Chenalhó que no podía enviar al ejército debido a que el general Montes se encontraba en Cancuc para tratar de controlar la rebelión en aquel pueblo. El secretario le pidió entonces diez carabinas para que los ladinos pudieran defenderse, ya que "los ánimos de los indígenas se encuentran bastante descontentos en contra mía y de todos los vecinos ladinos de la localidad, encontrándonos completamente escasos de armas para poder defender y garantizar las vidas e intereses de las familias residentes en este pueblo". Bonifaz replicó que tampoco era posible proporcionar las armas pues no disponían de las mismas. ${ }^{3}$

Ya fuera porque la situación en Los Altos resultaba realmente peligrosa o porque las autoridades municipales de Las Casas trataban de evitar la intervención de funcionarios estatales y federales, eran también frecuentes las cartas de advertencia del presidente municipal de esta ciudad a las instituciones agrarias y de salud, aconsejando que se abstuvieran de enviar inspectores a la zona dada la actitud hostil de los indígenas.

La institución que intentó con mayor ahínco incidir en la vida de los poblados indígenas fue sin duda la Secretaría de Educación Pública. Los maestros se enfrentaron a la resistencia — a veces armada - tanto de los finqueros como de las propias comunidades indígenas. En enero de 1935, Manuel Castellanos Castellanos fue nombrado inspector de SEP para la quinta zona de Chiapas, área vasta que comprendía desde Los Altos centrales hasta la selva Lacandona (Lewis 2005: 129). Llegó decidido a enfrentarse con los enganchadores, expendedores de alcoholes y contra los propios padres de familia, indígenas o mestizos, que se negaban a enviar a sus hijos a la escuela. Durante sus dos primeros años en el cargo, solicitaba reiteradamente mediante cartas al ayuntamiento de San Cristóbal refuerzo de la policía para desalojar a los expendedores de alcoholes que 
se instalaban cerca de las escuelas, y para cobrar multas a los padres que no querían "cumplir con el precepto constitucional de la Escuela Socialista Obligatoria"4 ${ }^{\text {. A pesar }}$ de ello, muchos poblados evitaron casi totalmente la influencia de la Secretaría de Educación. En 1935, en Chamula solo ocho niños iban a la escuela. Estos eran niños seleccionados por las propias comunidades para convertirse en escribanos municipales (Lewis 2005: 52). Diez años más tarde, el antropólogo Ricardo Pozas observaba que la escuela de ese municipio tenía inscritos a dieciséis niños de los cuales únicamente dos o tres asistían regularmente durante todo el año (Pozas 1977: 88).

El gobierno de Victórico Grajales (1932-1936) impulsó campañas de "incorporación de los indígenas a la civilización”, muchas de ellas patrocinadas por la Gran Masonería de Chiapas, sirvan de ejemplo la Campaña provestido del alumno indígena y la Campaña propantalón del jornalero indígena. ${ }^{5}$ Fundó también el Departamento de Acción Social, Cultura y Protección Indígena (DASCPI), el 18 de abril de 1934. En el Decreto 155, por el cual se creaba el Departamento, Grajales afirmaba:

\footnotetext{
Considerando que el mayor problema social que agobia y detiene la evolución económica de Chiapas es la existencia de las grandes masas indígenas que, representando $38 \%$ de nuestra población, son el lastre del progreso colectivo y el mayor obstáculo que se opone a la coordinación de todos los sectores de la vida social, encaminada a la realización del programa constructivo de la Revolución. ${ }^{6}$
}

Evidentemente, esta concepción del indígena en nada facilitaba un diálogo interétnico. La mutua desconfianza, la permanente amenaza y el conflicto latente privaron así, como desde hacía siglos, en las relaciones entre ladinos e indígenas. 


\section{CARDENISTAS Y ÉLITES LOCALES ASCENDENTES}

\section{(INDÍGENAS Y LADINOS)}

Durante el año 1935, la disputa entre el presidente Lázaro Cárdenas y el ex presidente Plutarco Elías Calles terminó con el exilio de este último y con una purga de los gobernadores y de los secretarios públicos conocidos por su cercanía política con Calles. A pesar de las fuertes campañas políticas en el Congreso de la Unión y en la prensa nacional contra Victórico Grajales, logró permanecer en el gobierno de Chiapas hasta septiembre de 1936. La oposición indigenista, agrarista y socialista, se organizó bajo la bandera del cardenismo. A medida que los callistas iban perdiendo terreno político, los grupos más cercanos a los terratenientes y comerciantes de Los Altos así como a la oligarquía chiapaneca, reaccionaron acercándose al gobernador y reforzando las guardias blancas mientras que los cardenistas se fueron radicalizando.

En 1936, la disputa entre ambas facciones estalló con motivo del cambio de gobernador. El candidato del presidente Lázaro Cárdenas, Efraín Gutiérrez, era un ingeniero agrónomo muy amigo suyo que había vivido durante veinticuatro años fuera del estado. Por su parte, Grajales impulsó como precandidato a Samuel León Brindis.

En la región de Los Altos, la campaña de Gutiérrez se basó, por un lado, en una sutil alianza con los grupos más cercanos a la jerarquía católica, anunciando una moderación de la agenda anticlerical; por otro lado, los cardenistas derogaron una ley por la cual los tsotsiles habían sido excluidos de las votaciones primarias del Partido Nacional Revolucionario - actual PRI- en Chiapas, con el argumento de que estaban intelectualmente incapacitados, e iniciaron una fuerte labor de propaganda para ganar el 
voto de las comunidades (Lewis 2005: 141-142). El encargado principal de esa campaña fue Erasto Urbina. Hasta entonces había sido un simple agente de migración comisionado en el pueblo fronterizo de Suchiate. Durante la campaña de Efraín Gutiérrez se volvió su hombre principal en Las Casas y en toda la región tsotsil tseltal, aprovechando su amistad con muchos de los comerciantes y artesanos de su natal barrio de Mexicanos así como sus amplios conocimientos de las lenguas indígenas y de las condiciones socioculturales regionales.

En mayo de 1936, el presidente de la República nombró una comisión intersecretarial para estudiar y resolver el problema relativo a la habilitación de los indígenas tsotsiles para trabajar en las fincas cafetaleras. Erasto Urbina fue nombrado miembro de la Comisión en representación de la Procuraduría General de la República, donde asumía temporalmente un cargo (Urbina 1944). Sin duda, uno de los propósitos de esta comisión fue reforzar el grupo de políticos y burócratas que apoyaba la campaña del precandidato cardenista. En efecto, sesionó en el palacio municipal de Las Casas, entre el 10 y el 17 de julio de 1936, con representantes del Departamento de Asuntos Indígenas, del Departamento del Trabajo, de las Secretarías de Economía, Educación, Comunicaciones y Agricultura, del Departamento Agrario, del de Salubridad, del Departamento Forestal, de la Procuraduría General de la República, así como el representante del Departamento de Acción Social, Cultura y Protección Indígena del estado de Chiapas, además con enviados de los distintos pueblos indígenas de la región. Las sesiones de la Comisión coincidieron con las votaciones para elegir al candidato del PNR, celebradas el 12 de ese mismo mes. ${ }^{7}$ 
El resultado más importante de esta reunión fue la firma de un contrato colectivo mediante el cual el Departamento de Asuntos Indígenas quedaba a cargo de la contratación temporal para las fincas cafetaleras del Soconusco, y los encargados directos de velar por los derechos de los indígenas serían los procuradores de comunidades indígenas del DAI. Asimismo, se acordó la formación de un Sindicato Único de Trabajadores de las Fincas Cafeteras como titular del contrato.

En gran parte gracias a la labor de base realizada por Erasto Urbina en Los Altos, el ingeniero Efraín Gutiérrez salió victorioso en las votaciones internas de PNR y por supuesto en la elección a gobernador. En los primeros meses de su gobierno, Urbina se dedicó rápidamente a situar a todos los miembros de su comité electoral en cargos municipales y empezó a organizar el Sindicato de Trabajadores Indígenas (STI), que afiliaría a trabajadores cafetaleros temporales tsotsiles y tseltales del Soconusco. El sindicato se fundó en la finca Maravillas, municipio de Tapachula, el 24 de diciembre de 1936 (Urbina 1944) pero no solicitaría su registro a la Junta Central de Conciliación y Arbitraje sino siete meses después. El 6 de febrero de 1937, Efraín Gutiérrez nombró a Erasto Urbina jefe de DASCPI. Ambos convinieron el traslado de las oficinas del Departamento a la ciudad de Las Casas. ${ }^{8}$ En julio de 1937 entraron en funciones las agencias de colocación, dependientes del Estado, en las ciudades de Las Casas, Comitán y Motozintla. Su objetivo era el de "prestar servicios gratuitos y conectar y relacionar obreros con empresas agrícolas cuidando que la contratación se hiciera conforme a las bases aprobadas en la convención intersecretarial"9. Además de ocuparse de la habilitación y contratación de los indígenas, las agencias les brindaban alojamiento y alimentación y trataban de evitar los robos y asaltos a chamulas que se encontraban en estado de ebriedad en la ciudad de Las Casas. Con la creación de las agencias, Erasto 
Urbina se aseguró el control total del proceso de contratación y traslado de los trabajadores indígenas hacia las fincas cafetaleras. En carta dirigida al presidente municipal de Las Casas, de 11 de julio de 1937, manifestaba así:

Por acuerdo expresado del C. Gobernador Constitucional del Estado, y en apoyo del Artículo 14 de la Ley Federal del Trabajo, con esta fecha ha quedado establecida en esta ciudad la AGENCIA GRATUITA DE COLOCACIONES adscrita al DASCPI, cuyas funciones tendrán por objeto relacionar a los trabajadores con las Empresas Agrícolas del Soconusco, substituyendo en esta función la intervención de Enganchadores o Habilitadores. Esta Agencia es la ÚNICA AUTORIZADA para intervenir en la contratación de peones que salgan a la región del Soconusco u otros centros de trabajo del Estado, teniendo además funciones de PREVISIÓN SOCIAL. ${ }^{10}$

El Sindicato de Trabajadores Indígenas no operó en la defensa de los trabajadores agrícolas de las fincas ubicadas en Los Altos de Chiapas. Sin embargo, DASCPI promovió en la región la organización de comités agraristas que tramitaron demandas de tierras y organizaron invasiones en las fincas. Hasta entonces, los escasos comités agraristas de Los Altos habían sido organizados por los maestros enviados desde SEP. ${ }^{11}$ Al ser trasladado DASCPI a ciudad Las Casas, los promotores del Departamento se convirtieron también en intermediarios políticos importantes. Algunos indígenas bilingües cercanos a Erasto Urbina, así como comerciantes y vendedores ambulantes que trabajaban para el Departamento, ocuparon puestos de secretarios municipales. En Chamula, el propio Urbina designó un grupo de escribanos, entre ellos Salvador Gómez Oso y Pascual Patishtán, que participó en el cabildo del pueblo y formó el comité de la reforma agraria, representando al comité regional en la Comisión Agraria Regional. ${ }^{12}$ Esos mismos indígenas asumieron funciones en la dirección de STI (Wasserstrom 1989: 202). De la misma manera, jóvenes indígenas bilingües que habían participado en el 
comité electoral en favor de Efraín Gutiérrez fueron desplazando a las antiguas autoridades tradicionales monolingües en comunidades como Cancuc, Mitontic y Tenejapa (íbid, pp. 213). La labor de los indigenistas permitió no solo cambios fundamentales en las estructuras de poder comunal, sino también una transformación de la base de la riqueza territorial en la región, de tal manera que $57.3 \%$ de la tenencia en 1944 era de tipo ejidal (íbid, pp. 198-200).

Otra de las causas asumidas por el indigenismo estatal fue la del control y monopolio de la venta de alcohol. Cabe señalar el énfasis que pusieron los funcionarios cardenistas en las campañas antialcohólicas en regiones indígenas. Así, transmitiendo las directivas del presidente de la República, en febrero de 1937 Efraín Gutiérrez envió una carta a los presidentes municipales donde exponía:

Acorde con la decidida política antialcohólica del C. Presidente de la República, General Lázaro Cárdenas, y del PNR, estima urgente y patriótico evitar por todos los medios posibles la venta legal y clandestina de alcohol en todos los pueblos de indios y en todas las colonias Agrarias del Estado, lugares donde los traficantes de la miseria y de la muerte pueden realizar mejor su nefasto comercio. $^{13}$

Sin embargo, el propio gobierno del estado promulgó ese mismo año una ley que permitía la venta de licor a las autoridades tradicionales de las comunidades $-\mathrm{o}$ a quienes pronto fueran a asumir cargos religiosos-. Así, la prohibición se transformó en promoción de un monopolio controlado por un grupo selecto de principales y ex principales que fueron concentrando un enorme poder económico y político (Wasserstrom 1989: 211). Por supuesto, el alcohol siguió fluyendo en grandes caudales hacia las comunidades tsotsiles de Los Altos. Nuevamente, el urbinismo logró de esta 
manera transformar una política antipopular promovida por el gobierno federal en un camino de ascenso y movilidad sociopolítica para indígenas y mestizos de Los Altos.

\section{DOS INDIGENISMOS EN CHIAPAS}

La práctica indigenista en Chiapas durante el gobierno de Cárdenas se desarrolló bajo dos caras institucionales distintas que respondían a estrategias e intereses políticos diferentes: el indigenismo del gobierno federal, a través del Departamento de Asuntos Indígenas; y el del gobierno estatal, mediante el Departamento de Acción Social, Cultura y Protección Indígena. El primero constituía uno de los fundamentos del nuevo nacionalismo revolucionario, impulsado por intelectuales cercanos al régimen. $\mathrm{Su}$ objetivo era "la integración a la nación" de los pueblos indígenas a través de la educación, la castellanización, proyectos productivos, organización de fiestas cívicas, entre los principales.

El indigenismo del gobierno estatal estaba poco preocupado por la "mexicanización" de los indios, y si bien pretendía transformar las estructuras locales de poder era sobre todo para abrir paso a un sector mestizo que había sido marginado de los cargos públicos. En realidad, el indigenismo estatal se mostraba tan reacio como las propias élites locales a la llegada de funcionarios federales que intentaban cambiar las reglas del juego sin tener en cuenta los intereses de los actores políticos de la región.

Ambos indigenismos compartían un discurso de carácter redentor que negaba toda una historia de explotación y opresión. La temática cardenista de los indígenas como pobres y explotados, como una raza oprimida y desposeída a lo largo de la historia mexicana, 
daría un giro a las políticas económicas, educativas, laborales y culturales en las regiones con alta densidad de población indígena en el país, en particular en Los Altos de Chiapas. Contra las ideas de los gobiernos anteriores y de las élites regionales, que percibían al indio ya fuera como un obstáculo para la modernización del estado, un elemento de la naturaleza o una posesión más de los finqueros. El Estado cardenista lo concibió como el ciudadano ideal de la nueva nación que emergía del despertar colectivista y socialista, gracias a sus características innatas que incluían coraje, fidelidad, frugalidad, virtud moral y habilidad para adaptarse al cambio (Dawson 1998: 285). Si bien hasta entonces los indígenas habían sido considerados objetos pasivos de las políticas que podían mostrarse más o menos refractarios a los intentos de integración racial o cultural, los políticos cardenistas empezaron a presentarlos como seres racionales, politizados y movilizados.

Adjetivar el indigenismo cardenista de racista o hablar incluso, como hace Alan Knight (2004: 28), de un "franco racismo a la inversa" tomando como base la exaltación —por parte de algunos funcionarios particularmente entusiastas- de las cualidades superiores del indígena sobre el blanco o el mestizo, nos impide ver el giro fundamental que da no solo el discurso nacionalista sino sobre todo la práctica política en las regiones indígenas durante esta época. ${ }^{14}$

Es cierto que el argumento contrario de los cardenistas partía - como los anteriores discursos políticos sobre el indígena- de una naturalización de las características culturales de indios y blancos mediante una mitificación del indígena como fundamento de la identidad nacional. Pero el reconocimiento de la situación de explotación que padecían los indígenas del país y su comprensión como una "clase social”, que los hacía 
equivalentes a los mestizos pobres, representó un cambio sustancial en el discurso y en la política. Los cardenistas rescataron demandas sentidas por las comunidades, como la dotación de tierras y créditos. En muchas ocasiones, formaron comités agraristas: en la región de Los Altos de Chiapas podríamos hablar incluso de un "agrarismo indigenista" ${ }^{, 15}$.

El Departamento de Asuntos Indígenas fue fundado al concluir 1934, poco después de asumir la presidencia Lázaro Cárdenas. Por ley de 30 de diciembre de ese año, el Departamento pasó a formar parte de las dependencias del ejecutivo federal; orientaría su labor a "estudiar los problemas fundamentales de las razas aborígenes", además de “promover y gestionar ante las autoridades federales y las de los Estados, todas aquellas medidas o disposiciones que conciernen al interés general de los núcleos aborígenes de población"16. Entre las primeras acciones llevadas a cabo por DAI se encontraban la "campaña a favor del indio del estado de Chiapas" y la "campaña de liberación del trabajador de las fincas cafeteras"17. Ambas tuvieron lugar en 1936, después de una serie de visitas a la región cafetalera del Soconusco y a Los Altos.

En febrero de 1936, el Departamento envió a la ciudad de Las Casas a Armando Arvea Jiménez, originario de Guerrero, como procurador de comunidades indígenas. En carta de 11 de ese mes, dirigida al presidente municipal, le comunicaba:

Tengo el honor de participar a Usted que por órdenes del H. Departamento de Asuntos Indígenas, se ha establecido en esta ciudad la Procuraduría dependiente del mismo para atender a las clases indígenas de acuerdo con el programa de acción que se ha trazado, siendo su principal objeto el de incorporar a la raza indígena de nuestro país al movimiento no interrumpido del progreso, mediante la elevación de su nivel económico, intelectual y moral... ${ }^{18}$ 
En abril de 1936, el Departamento elaboró un boletín relacionado con la situación indígena en Chiapas en el que se exponía un largo enunciado de las formas de explotación caracterizadas por el "esclavismo", así como las irregularidades cometidas contra los jornaleros indígenas originarios de Los Altos de Chiapas en su camino hacia la costa del Pacífico y en las fincas cafetaleras. En julio de ese mismo año, participó en la comisión intersecretarial nombrada por el presidente Lázaro Cárdenas para estudiar y resolver la situación de los trabajadores indígenas de las fincas cafetaleras.

De acuerdo con la reunión de la Comisión celebrada en julio de 1936, el primero de febrero de 1937 se fundó en Chamula el Sindicato Único de Trabajadores de las Fincas Cafeteras del Soconusco (SUTFCS), que adquirió la titularidad del contrato colectivo. Este sindicato tenía los mismos afiliados que el propio STI, duplicando así sus funciones. ${ }^{19}$ A medida que DASCPI, STI y las agencias gratuitas de contratación controlaban el proceso de habilitación de los trabajadores indígenas, DAI y SUTFCS se vieron desplazados de sus atribuciones. Al poco tiempo, los propios dirigentes de este sindicato, Salvador Gómez, secretario general, y Nicolás Espinosa, secretario de conflictos, pidieron la cancelación de su registro. En carta de 15 de julio de 1937, dirigida al presidente de la Junta Central de Conciliación y Arbitraje del Estado, exponían las razones que los llevaban a dicha solicitud:

1. ${ }^{\circ}$ Que desde la fecha de constitución del SUTFCS, este ha sido manejado dictatorialmente por el C. Procurador de Comunidades Indígenas de esta ciudad de Las Casas.

2. ${ }^{\circ}$ Que el SUTFCS, en su fundación, aceptó ser asesorado por la Procuraduría de Comunidades Indígenas, siendo obligación de ésta el haberlo orientado, para encarrilarlo al medio sindical, asesorarlo en sus conflictos, y no abrogarse la facultad netamente de la incumvencia (sic) de su Comité Ejecutivo. ${ }^{20}$ 
Manifestaban de igual manera que desde la fecha de su fundación, SUTFCS no había celebrado sesión alguna y que el C. Armando Arvea, procurador de comunidades indígenas en ciudad las Casas, "desconociendo nuestro dialecto indígena ha ocasionado el SUTFCS, una constante serie de dificultades, con grave perjuicio para sus coasociados" ${ }^{, 21}$.

En una carta al presidente con fecha 10 de agosto de 1938, el jefe de DAI, Graciano Sánchez, denunciaba que en la contratación de indígenas en Los Altos habían dejado de intervenir los procuradores de comunidades indígenas de acuerdo con lo que se había fijado en el contrato de trabajo de 17 de julio de 1936, y que los propietarios de las fincas consideraban terminado ese contrato colectivo y disuelto el Sindicato. ${ }^{22}$

El 13 de septiembre de ese mismo año, el gobernador Gutiérrez le escribió una carta al presidente Lázaro Cárdenas para desmentir lo contenido en el informe de Graciano Sánchez. El desmentido reflejaba sin embargo con toda claridad la duplicación de tareas entre DAI y DASCPI y la subordinación de los procuradores a las agencias de colocación:

Me complace informar sobre los particulares, para el superior conocimiento del ciudadano presidente, que es inexacto que las contrataciones se realicen en forma individual, pues como podrá usted ver por el Contrato que me permito adjuntarle, la contratación es colectiva y se hace directamente entre los mismos representantes del comité ejecutivo del Sindicato de Chamulas y las Empresas que solicitan sus servicios. En dicho Contrato se han conservado todas las conquistas alcanzadas por la comisión intersecretarial celebrada en Ciudad Las Casas en 1936. La Agencia de Colocaciones y el Departamento de Asuntos Indígenas del Estado intervienen vigilando el exacto cumplimiento de los términos del Contrato y la humanización de los tratos para los indígenas 
contratados; y, por lo demás, al Procurador de Asuntos Indígenas de Ciudad Las Casas no se le ha negado ninguna intervención. A él mismo le consta que las autoridades del Trabajo tienen instrucciones precisas de atenderlos y de aceptar toda la colaboración que en beneficio de la raza indígena puedan prestar. $^{23}$

El procurador de Asuntos Indígenas se limitaba a denunciar reiteradamente — topándose generalmente con oídos sordos- prácticas hasta entonces comunes en Las Casas, como el asalto a los indígenas que llegaban a vender sus mercancías al mercado de la ciudad, la venta ilegal de aguardiente y la concentración de jornaleros en grupos de cuatrocientas y quinientas personas durante días en recintos cerrados, donde dormían y comían escasamente en lo que se realizaban los trámites y arreglos para la salida de la caravana hacia la región del Soconusco. ${ }^{24}$

Mientras tanto, a través del sindicato y de las agencias gratuitas de contratación, DASCPI fue sustituyendo la labor de los enganchadores y asumiendo los beneficios económicos y políticos de la contratación. Mientras que DAI se había comprometido a cancelar las deudas de los trabajadores temporales de las fincas, algunas de las cuales se habían heredado de padres a hijos; DASCPI se encargó de establecer una vigilancia estricta en el cumplimiento de los contratos y en el saldo de las deudas por parte de los indígenas. El Sindicato contaba así con un registro extenso de todos los trabajadores contratados en las fincas, sus deudas respectivas, las de sus padres, y los días trabajados. Por intermediación de las autoridades municipales, recurría a la policía local para distribuir las boletas de trabajo y contratar el número de trabajadores requerido así como para detener e incluso llevar a la cárcel a quienes huían de las fincas antes de cumplir con sus contratos (Rus 1995). 
El nuevo sistema oficial desplazó a los enganchadores en un proceso sin duda violento y conflictivo. Por ejemplo, el diputado Erasto Urbina se dirigía el 10 de agosto de 1939 al presidente municipal de Larráinzar, Chiapas, informándole:

Por denuncia presentada a este Departamento, tiene conocimiento de que el Sr. Saúl Montoya que radica en este lugar se encuentra habilitando gente para ir a prestar sus servicios a la zona cafetera. Suplico a Usted de una manera muy especial se sirva ejercer una vigilancia estricta a efecto de comprobar esta denuncia que, de ser cierta deberá consignar a las personas que se dediquen a contratar gente sin la intervención de la Agencia Gratuita de Colocaciones, Oficina creada por el Gobierno del Estado, con el fin de evitar la explotación del indígena y cuya única oficina está autorizada para intervenir en la contratación colectiva de los trabajadores. ${ }^{25}$

Los indígenas de Los Altos también fueron impedidos de llegar a buscar empleo a la zona cafetalera por su propia cuenta sin cumplir con los trámites impuestos por las agencias, como se evidencia en cartas dirigidas por Urbina al gobernador del estado solicitando la intervención de los inspectores de trabajo para verificar si habían llegado a emplearse en las fincas "indígenas que han salido subresticiamente (sic), sin llevar los requisitos establecidos por el superior gobierno, y que rigen a las agencias gratuitas de colocaciones". Solicitaba asimismo que en caso de comprobarse esa falta, se les aplicara a las empresas las sanciones marcadas por la ley. ${ }^{26}$

En 1940 se recrudeció nuevamente el conflicto entre los indigenistas federales y los del estado, con motivo de la realización de Congreso Regional Indígena en Las Casas, promovido por el presidente Lázaro Cárdenas. Luis Chávez Orozco, director en aquel momento de DAI, encargó a Ángel M. Corzo la organización del evento. Este utilizó todos los medios políticos para mantener al margen del Congreso a Erasto Urbina y al 
propio gobernador del estado, Efraín Gutiérrez. En respuesta, Urbina trató de imponer los secretarios municipales cercanos a DASCPI y los líderes de STI como delegados del Congreso; desarrolló además una campaña de ataques contra el Departamento de Asuntos Indígenas y contra Corzo, y trató de impedir u obstaculizar el uso de las instalaciones del palacio municipal por parte del equipo organizador (Lewis 2005: 192193).

El Congreso Regional Indígena marca el momento culminante del conflicto entre ambas instituciones, pero también el inicio de la decadencia del propio indigenismo cardenista, tanto en Chiapas como en el resto del país. En efecto, al poco tiempo terminaría el mandato de Cárdenas y Manuel Ávila Camacho asumiría la presidencia, dando marcha atrás a varias de las políticas reformistas y pluralistas que había promovido hasta entonces DAI.

\section{LA REACCIÓN DE LA VIEJA ÉLITE CRIOLLA}

El ascenso del indigenismo urbinista en Los Altos se dio en un contexto de particular conflictividad y frente a una fuerte reacción de la vieja élite local, reagrupada en torno al antiguo general de la rebelión delahuertista, Alberto Pineda Ogarrio. Si bien Efraín Gutiérrez había obtenido en la región la mayoría de los votos para el gobierno del estado - gracias a la votación de los municipios indígenas-, el candidato único a la presidencia municipal en 1936 fue Alberto Pineda, un importante finquero de la región y fuerte adversario político del ingeniero Gutiérrez. A pesar del aparente consenso para su candidatura. ${ }^{27}$ 
El camino por el que se hizo cargo del ayuntamiento fue particularmente violento: en septiembre de ese año, irrumpió con un grupo de hombres armados en las instalaciones de PNR y mandó apresar a Wistano Molina, secretario del comité municipal del partido. Se registró ilegalmente e impidió el registro de cualquier otro candidato. ${ }^{28}$

Gracias a la concentración del poder político y administrativo en la propia ciudad de Las Casas, cuando Pineda asumió la alcaldía pudo emprender una verdadera cruzada contra maestros, agraristas e indigenistas y dio rápidamente marcha atrás a las campañas anticlericales. Durante los primeros meses de 1937, ordenó la reapertura de varios templos de la ciudad y permitió que los sacerdotes oficiaran misas, violando así la ley de cultos. ${ }^{29}$ En marzo, los habitantes de ciudad Las Casas y finqueros regionales se quejaban de que Gutiérrez pretendía destituir a Pineda. ${ }^{30}$ El primero de mayo de ese año, un grupo de fervientes católicos identificados como seguidores del presidente municipal, reprimió la manifestación organizada por PNR y DASCPI, golpeando a obreros y campesinos. A su vez, el gobierno del estado advertía que Pineda hacía acopio de armas "con el propósito de fomentar un movimiento sedicioso, tomando como pretexto la libertad religiosa, y aviesamente fomentar las rivalidades que hoy por hoy pueden considerarse desaparecidas en tierra fría y tierra caliente"31. Finalmente, el 21 de julio, el congreso local decretó la desaparición de poderes en el ayuntamiento de Las Casas "por violaciones a los artículos 5 y 130 de la Constitución federal y 69 de la Constitución local, a la Ley sobre Cultos del Estado e innumerables quejas de persecución llevadas a cabo contra campesinos y obreros" ${ }^{\text {,32 }}$. El diputado Isidro Rabasa fue nombrado presidente municipal sustituto y el propio Erasto Urbina asumió una regiduría. $^{33}$ 
La destitución de Pineda causó verdadero júbilo entre los indigenistas. En agosto de 1937, los dirigentes del Sindicato de Trabajadores Indígenas solicitaron su registro ante la Junta Central de Conciliación y Arbitraje del Estado, más tarde el sindicato empezó a trabajar en estrecha colaboración con DASCPI y las agencias gratuitas de contratación, en las propias instalaciones del palacio municipal, con apoyo total de Isidro Rabasa. Parecía garantizada la hegemonía de esta élite ascendente.

Pero el presidente municipal depuesto interpuso una demanda de amparo ante la Suprema Corte de Justicia, al considerar que su destitución violaba el artículo 115 constitucional —la autonomía municipal—, y en marzo de 1938 la corte falló en su favor. El 24 de abril llegó al palacio municipal con la ejecutoria en mano, acompañado de los miembros de su ayuntamiento y de varios notables locales, y trató de retomar posesión de su cargo, pero se lo impidieron los hombres de Isidro Rabasa, parapetados con armas en el palacio. ${ }^{34}$ El 8 de mayo de 1938, a solicitud expresa de la corte, Efraín Gutiérrez envió dos representantes para hacer efectiva la ejecutoria de la Suprema Corte.

En los meses siguientes privaba en Los Altos una situación de guerra, con enfrentamientos continuos entre pinedistas e indigenistas. El gobierno del estado mandó militarizar la zona argumentando que los pinedistas habían "instigado a elementos fanáticos". Los habitantes de la ciudad denunciaban la situación caótica en que se encontraban y los maltratos sufridos por los partidarios del presidente municipal a manos de policías estatales y de militares. ${ }^{35}$ Los indigenistas advertían que Pineda estaba organizando una revuelta contra el gobierno cardenista y armando a sus partidarios. 
Las campañas para diputados al Congreso local enfrentaron a los dos bandos; por el lado de los indigenistas y de la Liga Regional de Comunidades Agrarias, los candidatos eran Erasto Urbina y Manuel Castellanos, mientras que Adolfo C. Corzo se constituía candidato de los pinedistas. Los meses de campaña se vieron continuamente sacudidos por confrontaciones armadas y acusaciones mutuas. Urbina y Castellanos contaban con el apoyo de todo el aparato institucional de PRM y de las confederaciones oficiales, mientras que Corzo tenía de su lado a los comerciantes criollos y finqueros de Los Altos, también por supuesto a la Iglesia católica.

El conflicto llegó a su apogeo en junio de 1938, cuando la policía municipal disparó varios tiros contra Erasto Urbina, quien había acudido al palacio municipal con un grupo de líderes indígenas. El intento de asesinato de Urbina fue un detonador de la movilización indígena en la región. El propio Urbina narraba así los hechos:

El 13 de junio me fueron disparados más de doscientos balazos: la policía municipal y los fanáticos me atacaban, pero afortunadamente su propio miedo hacía que el pulso les temblara y no pudieron de momento hacerme nada. La noche de ese mismo día las Fuerzas Federales protegían mi vida, y con este motivo, el día 14, miles de indígenas rodeaban la ciudad por distintas partes para rescatarme y llevarme a sus montañas ... El Presidente Municipal huyó de la Ciudad, la policía y los pistoleros fueron desarmados y yo, no obstante que me encontraba herido en un dedo de la mano izquierda y con un pie dislocado, salí en un carro sin capacete para hablar con los Jefes de las distintas tribus indígenas a efecto de que vieran que me encontraba vivo y que no se me tenía preso como se rumoraba. No obstante haber convencido a los indígenas, dejaron en mi domicilio un resguardo que se relevaba cada veinticuatro horas (Urbina 1944: 45). 
Cuando Urbina acudió al palacio municipal, estaba de hecho ausente de la ciudad Alberto Pineda y había dejado como interino a Ciro Coello. Por supuesto, la versión del presidente interino distaba mucho de la de Urbina: aquel aseguraba que este, encabezando a un grupo de pistoleros, había agredido a la policía municipal y herido de gravedad a uno de sus miembros, y solicitaba apoyo de las fuerzas federales para defender la presidencia municipal.

A pesar de las acusaciones de Urbina y de decenas de cartas enviadas al presidente Lázaro Cárdenas, denunciando "el intento de asesinato", Alberto Pineda permaneció formalmente en su cargo hasta el final de su mandato, aunque pidió licencia reiteradamente y pasó la mayor parte del periodo en la ciudad de México. Por otro lado, los pinedistas no lograron evitar la victoria de Erasto Urbina y Manuel Castellanos y su llegada al Congreso del estado. El nuevo presidente municipal electo a finales de 1938 fue el profesor Manuel Castellanos.

Así, durante los dos últimos años de la presidencia de Lázaro Cárdenas —y del gobierno de Efraín Gutiérrez en Chiapas- los indigenistas locales habían logrado desplazar a los terratenientes criollos y dirigían diversas instituciones regionales. Con todo un aparato institucional, controlaban las fuentes más importantes de ingreso de ciudad Las Casas; es decir, el proceso de contratación de mano de obra hacia las plantaciones de las tierras bajas y la venta al menudeo de alcohol en las comunidades. Trabajaban en coordinación con una pequeña élite indígena bilingüe que dirigiría la mayoría de los ayuntamientos indígenas y controlaría el sistema de cargos en muchos municipios de Los Altos durante varios decenios. 
Sin embargo, el indigenismo había perdido el entusiasmo reformista con el que irrumpió, pocos años antes, en las estructuras de poder de la región. Los urbinistas ocupaban puestos de funcionarios en las distintas instituciones del Estado. Al final de la década de los treinta, Isidro Rabasa había regresado a Tuxtla Gutiérrez donde dirigiría el refundado Partido de la Revolución Mexicana. En 1940, el profesor Manuel Castellanos ya no acusaba a los ladinos —en particular a enganchadores y expendedores de alcohol— y se quejaba en cambio reiteradamente de la falta de disposición de los propios indígenas para la educación y la higiene; pedía a los maestros bajo su jurisdicción que trataran de instruir a sus alumnos en principios morales para "forjar en los indios sentimientos y hábitos que los hagan más humanos" (Lewis 2005: 187).

\section{CONCLUSIONES}

El indigenismo cardenista logró renovar las estructuras de poder en Los Altos de Chiapas al permitir la formación de una clase política de origen popular que iría acomodándose, a lo largo de los siguientes años, en las instituciones regionales posrevolucionarias. De 1936 a 1938 el ascenso de este grupo se dio en un contexto de fuertes conflictos interétnicos y de violencia política. También esos fueron los años del mayor reparto agrario: se crearon docenas de ejidos en una redistribución que provocó enfrentamientos armados no solo entre comunidades y hacendados, sino también entre las propias comunidades indígenas (Pozas 1977, Lewis 2001). El empate de las políticas indigenistas con el agrarismo fue probablemente el aspecto más radical y popular del cardenismo en Chiapas, al potenciar la movilización y organización campesina en la región de Los Altos. 
Distintos autores han resaltado que esta labor populista era considerada como un vasto potencial de apoyo electoral al régimen posrevolucionario en sus distintos niveles de gobierno (Reséndiz y Casas 1995). Las elecciones de 1936 y de 1938 parecen confirmar esa hipótesis. Se ha considerado también que las reformas sociales implementadas por los cardenistas formaban parte de una estrategia nacional para controlar, a través del Partido de la Revolución Mexicana, las organizaciones campesinas, las relaciones laborales y los sistemas de autoridad en las regiones indígenas (Collier 1987: 91). Indudablemente, el indigenismo facilitó la corporativización de algunas comunidades tsotsiles y su integración al partido oficial y al Estado federal, pero provocó también en muchos pueblos un retraimiento comunitario y una reacción violenta contra la intervención de agentes ladinos, ya fueran chiapanecos o de otros lugares de la república.

Si bien la situación socioeconómica de los indígenas siguió siendo precaria, algunas reformas sociales fueron modificando, poco a poco, las formas más agudas de subordinación, tales como las tiendas de raya, los castigos físicos, el trabajo no pagado, la reclusión de los indígenas habilitados y el viaje a pie al Soconusco en terribles condiciones físicas. Los indigenistas chiapanecos, agrupados en torno a Erasto Urbina, lograron además cambios en la estructura agraria y afectaron aspectos nodales de la política regional. El indigenismo estatal permitió así el ascenso de una pequeña élite mestiza a la administración pública y a puestos de elección popular en el municipio de Las Casas y en el estado. También dio lugar a la formación de nuevos líderes indígenas, educados muchas veces en los internados y en las escuelas de la Secretaría de Educación Pública, que ocuparían, durante las décadas siguientes, cargos políticos y religiosos en sus municipios. Muchos de estos indígenas se volvieron intermediarios en 
el sistema de enganche y en el comercio al menudeo del aguardiente. Adquirieron así un capital considerable que les permitiría integrarse a la pequeña burguesía agraria y comercial de la región (Pozas 1977).

Al final del gobierno cardenista, el indigenismo moderó considerablemente sus discursos revolucionarios, sus políticas reformistas y sus afanes nacionalistas. Se retiró el escaso apoyo que las procuradurías de asuntos indígenas habían brindado a los trabajadores habilitados en sus comunidades o en Las Casas y a los pequeños comerciantes indígenas. DAI empezó a perseguir a los elementos más radicales. Ángel Corzo, quien asumió el cargo de oficial mayor en el Departamento, acusó a algunos empleados de tendencias comunistas (Lewis 2005: 193). En el mismo tenor, los indigenistas chiapanecos limitaron cada vez más sus funciones a la intermediación laboral, educativa y cultural, entre las comunidades indígenas y las élites políticas y económicas del estado, y dejaron de lado las denuncias a la explotación y opresión de la "raza" indígena. 


\section{BIBLIOGRAFÍA}

\section{Archivos}

Archivo del Centro de Estudios de Historia de México. CONDUMEX, México, D.F.

Archivo General de la Nación. Ramo Presidentes. México, D.F.

Archivo Municipal de San Cristóbal de Las Casas. San Cristóbal de Las Casas, Chiapas.

Archivo Personal de Prudencio Moscoso Pastrana. San Cristóbal de Las Casas, Chiapas.

Centro Universitario de Información y Documentación (CUID), Acervos Especiales y Archivo Histórico. UNICACH, Tuxtla Gutiérrez.

Revisión hemerográfica

Hemeroteca Fernando Castañón Gamboa. Universidad de Ciencias y Artes de Chiapas (UNICACH), Tuxtla Gutiérrez, Chiapas.

Revisión documental

Primer Informe de Gobierno del Ingeniero Efraín Gutiérrez, 1. ${ }^{\circ}$ de noviembre de 1937. Tuxtla Gutiérrez, Chiapas.

Departamento de Asuntos Indígenas, Memoria del 1. ${ }^{\circ}$ de enero al 31 de agosto de 1936. Informe que el DAI presenta a la Presidencia de la República acerca de los trabajos desarrollados por el propio departamento durante el periodo que terminó el 31 de agosto de 1936. México, D.F.

Departamento de Asuntos Indígenas, Memoria del 1. ${ }^{\circ}$ de septiembre de 1936 al 31 de agosto de 1937. Informe que el DAI presenta a la Presidencia de la República acerca de los trabajos desarrollados por el propio departamento durante el periodo que terminó el 31 de agosto de 1937. México, D.F.

Periódico Oficial del Estado de Chiapas, tomo LI, núm. 16, abril de 1934. Tuxtla Gutiérrez, Chiapas.

Publicaciones

Benjamin, Thomas, 1990, El camino a Leviatán: Chiapas y el Estado mexicano, 18911947. Consejo Nacional para la Cultura y las Artes, México.

Collier, George A., 1987, "Peasant Politics and the Mexican State: Indigenous Compliance in Highland Chiapas". Mexican Studies, vol. 3, núm. 1, winter. University of California Press.

Dawson, Alexander S. 1998, "From Models for the Nation to Model Citizens: Indigenismo and the 'Revindication' of the Mexican Indian, 1920-40". Journal of Latin American Studies 30. UK. 
Favre, Henri, 1984, Cambio y continuidad entre los mayas de México. CONACULTAINI, México. (Colección Presencias.)

García de León, Antonio, 1985, Resistencia y utopía. Memorial de agravios y crónica de revueltas y profecías acaecidas en la provincia de Chiapas durante los últimos quinientos años de su historia, tomo 2. Era, México.

Knight, Alan, 2004, "Racismo, revolución e indigenismo: México, 1910-1940". En Cuadernos del Seminario de Estudios sobre el Racismo en/desde México, núm. 1, coordinado y editado por José Jorge Gómez Izquierdo. Universidad Autónoma de Puebla-Consejo Estatal de Ciencia y Tecnología, Puebla.

Lewis, Stephen E., 2001, "A window into the Recent Past in Chiapas: Federal Education and Indigenismo in the Highlands, 1921-1940". Journal of Latin American Anthropology, vol. 6, núm. 1, pp. 58-84. UK.

Lewis, Stephen E., 2005, The Ambivalent Revolution. Forging State and Nation In Chiapas, 1910-1945. University of New Mexico Press, New Mexico.

Moscoso Pastrana, Prudencio, 1960, El pinedismo en Chiapas. Editorial Cultura, México. (Edición a cargo del autor.)

Pozas Arciniega, Ricardo, 1977, Chamula, tomo 2. Instituto Nacional Indigenista, Clásicos de la Antropología Mexicana, México.

Reséndiz, Ramón y María Cristina Casas, 1995, “Cuarta Parte: 1911-1940”. En Historia del H. Congreso del Estado de Chiapas, coordinado por Carlos Ruiz Abreu. Congreso del Estado, Tuxtla Gutiérrez.

Rus, Jan, 1995, "La comunidad revolucionaria institucional: la subversión del gobierno indígena en Los Altos de Chiapas, 1936-1968". En Chiapas: los rumbos de otra historia, editado por Mario Ruz y J.P. Viqueira. UNAM-CIESAS-CEMCA-UdeG, México.

Urbina, Erasto, 1944, El despertar de un pueblo. Memorias relativas a la revolución indígena en el estado de Chiapas. Mecanografiado. Archivo Prudencio Moscoso Pastrana. San Cristóbal de Las Casas, Chiapas.

Wasserstrom, Robert, 1989, Clase y sociedad en el centro de Chiapas. Fondo de Cultura Económica, México. 


\section{Notas}

${ }^{1}$ Este artículo constituye un avance de la investigación financiada por CONACYT titulada "Integrados y marginados en la construcción del Estado mexicano posrevolucionario. Una investigación de los juegos de poder locales y sus nexos con la política nacional, 1920-1950”.

${ }^{2}$ En marzo de 1933 el Congreso del estado decretó que los nombres de los santos serían suprimidos de todos los poblados, calles y plazas públicas. La medida no fue revertida sino hasta 1943 (Lewis 2005).

${ }^{3}$ AMSC. Caja 3/20. Expediente 47. Año 1935. "Relativo a los disturbios indígenas ocurridos en el Pueblo de Cancuc".

${ }^{4}$ AMSC. Caja 1/13. Expediente 28. Año 1936.

5 "Discurso que el Profesor Angel M. Corzo pronunció en la segunda reunión masónica celebrada en Ciudad Las Casas", periódico Liberación, Tuxtla Gutiérrez, 2 de junio de 1935.

${ }^{6}$ Periódico Oficial del Estado de Chiapas, tomo LI, núm. 16, 18 de abril de 1934. Tuxtla Gutiérrez.

7 AMSC. Caja 3/13. Expediente72. Año 1936; Archivo General de la Nación (en adelante AGN). Presidentes. LCR. 533.31/9.

${ }^{8}$ Primer Informe de Gobierno del Ingeniero Efraín Gutiérrez, 1. ${ }^{\circ}$ de noviembre de 1937. Tuxtla Gutiérrez, Chiapas.

${ }^{9}$ AGN. Ramo Presidentes. Lázaro Cárdenas del Río. 702.2/7789.

${ }^{10}$ AMSC. Caja 5/13. Expediente 78. Año 1937.

${ }^{11}$ De acuerdo con Stephen Lewis (2001), Manuel Castellanos Castellanos, inspector de educación en la región tsotsil tseltal durante 1935, estableció a través de la labor de los maestros, ocho comités agraristas en el primer bimestre de ese año a pesar de la resistencia no solo de los finqueros, sino también de las propias comunidades indígenas.

${ }^{12}$ AMSC. Caja 3/13. Expediente 37. Año 1937.

${ }^{13}$ Carta de 1. ${ }^{\circ}$ de febrero de 1937 de Efraín Gutiérrez a los presidentes municipales. Centro Universitario de Información y Documentación (CUID). Acervos Especiales y Archivo Histórico. Caja sin número. UNICACH, Tuxtla Gutiérrez.

${ }^{14}$ Existe desde luego un modelo discursivo hegemónico en el que se ubican tanto el discurso heterofóbico prerevolucionario como el discurso heterofílico posrevolucionario. Sin embargo, considerando que eran generalmente intelectuales mestizos los que exaltaban la "superioridad del indígena" y que esa exaltación no se tradujo nunca en una práctica de dominación u opresión racial del indígena sobre el mestizo, me parece equivocado hablar de "racismo a la inversa".

${ }^{15}$ Esto pondría en cuestión también la idea, planteada por Alan Knight (2004), de que el indigenismo se parecía al anticlericalismo por ser una política impuesta desde arriba, sin ninguna raigambre popular, a diferencia del agrarismo. En realidad, los comités agraristas de Los Altos de Chiapas fueron formados casi todos por los maestros de SEP o por los funcionarios del Departamento de Acción Social, Cultura y Protección Indígena, entre 1936 y 1940.

16 "Memorias del Departamento de Asuntos Indígenas, del 1. de enero al 31 de agosto de 1936", CONDUMEX.

17 "Memorias del Departamento de Asuntos Indígenas, del 1. o de septiembre de 1936 al 31 de agosto de 1937". CONDUMEX.

${ }^{18}$ AMSC. Caja 1/13. Expediente 6. Año 1936.

19 "Ya no habrá más enganchadores". Chiapas Nuevo, 24 de febrero de 1937. Tuxtla Gutiérrez.

${ }^{20}$ AMSC. Caja 5/13. Expediente 78. Año 1937.

${ }^{21}$ Ibídem.

22 AGN. Ramo Presidentes. Lázaro Cárdenas del Río. 533.31/9.

${ }^{23}$ AGN. Ramo Presidentes. Lázaro Cárdenas del Río. 533.31/9.

${ }^{24}$ AMSC. Caja 2/13. Expediente51. Año 1936; Caja 3/13. Expedientes 72 y 79; Caja 4/13. Expediente 98; Caja 5/13. Expediente114.

${ }^{25}$ Expediente titulado "Relación detallada de los trabajos desarrollados durante el mes de agosto de 1939, en el Departamento de Acción Social, Cultura y Protección Indígena, de acuerdo con el artículo 16 del reglamento de sus funciones, en concordancia con los artículos 46 y 47 que corresponden a las agencias de colocaciones". Archivo Personal Moscoso Pastrana.

${ }^{26}$ Íbid.

${ }^{27}$ De acuerdo con un telegrama enviado por el presidente estatal de PNR al gobernador, el día 11 de octubre de 1936, en las elecciones internas a la candidatura del partido para la presidencia municipal, "triunfó por unanimidad la planilla encabezada por C. Alberto Pineda O. Pues no hubo más candidatos" (AMSC. Caja 4/13. Expediente 98. Año 1936).

${ }^{28}$ AMSC. Caja 3/13. Expediente 91. Año 1936. 
${ }^{29}$ AGN. Presidentes. LCR. 544.5/496. Carta de Efraín Gutiérrez al presidente de la república de 19 de julio de 1937, explicando los motivos por los cuales había solicitado su destitución al Congreso local.

${ }^{30}$ AGN. Presidentes. LCR. 544.5/496 y 703.4/205.

${ }^{31}$ Ibídem.

${ }^{32}$ AGN. Presidentes. LCR. 544.5/496. "Telegrama al Presidente de la República, del Diputado Gustavo Gutiérrez R. y del Diputado Venancio Corzo, Presidente y Secretario del H. Congreso Local, Tuxtla Gutiérrez, Chiapas, 21 de Julio de 1937”.

${ }^{33}$ Manuel Castellanos fue nombrado síndico del ayuntamiento sustituto pero renunció al cargo (AMSC. Caja 5/13. Expediente 79. Año 1937)..

${ }^{34}$ AMSC. Caja 1/11. Expediente 9. Año 1938.

${ }^{35}$ AGN. Presidentes. LCR. 544.5/496. 